\title{
Evaluation of In Vitro Equivalence of Commonly Available Generic Brands of Amlodipine Tablets in Saudi Arabia Under Biowaiver Conditions
}

\author{
Asim Najmi ${ }^{1}$, Mohammed Al Bratty ${ }^{1}$, Bassam Abdullah Al-Bassam ${ }^{1}$, Rami Ali Aseri ${ }^{1}$, Turki \\ Suliman Wadani ${ }^{1}$, Abdulrahman Ibrahim Al-Muntashiri ${ }^{1}$, Hassan A. Alhazmi ${ }^{1,2}$, Muhammad $\mathrm{H}$. \\ Sultan ${ }^{3}$, and Sadique A. Javed ${ }^{1 *}$ \\ ${ }^{1}$ Department of Pharmaceutical Chemistry, College of Pharmacy, Jazan University, Jazan, Saudi Arabia. \\ ${ }^{2}$ Substance Abuse and Toxicology Research Centre, Jazan University, Jazan, Saudi Arabia. \\ ${ }^{3}$ Department of Pharmaceutics, College of Pharmacy, Jazan University, Jazan, Saudi Arabia.
}

e-mail: sajaved@jazanu.edu.sa; sadique.javed1980@gmail.com

\section{ABSTRACT}

When a medicine is not able to treat the disease for which it was intended, as in case of substandard and falsified drug products, it may prolong the disease and in worst scenario, the patient may die because of the untreated illness or the product itself. To ensure the quality and safety of medicine, WHO recommends timely evaluation of pharmaceutical quality. The present study is an attempt to evaluate the pharmaceutical properties and in vitro drug release of four generic brands and one innovator product (Norvasc) of amlodipine tablets ( $5 \mathrm{mg}$ ) according to USP and WHO guidelines. The products passed the compendial specifications of weight variation ( $<5 \%$ deviation), friability ( $<1 \%$ weight loss), and assay (90-110\% of labeled amount). The tablets were fast-disintegrating, as complete disintegration observed in 1.20-1.64 min. The dissolution profiles of the generic products were equivalent to the innovator brand in $\mathrm{pH} 1.2 \mathrm{HCl}$ and acetate buffer ( $\mathrm{pH} 4.5$ ) without statistical treatment ( $\geq 85 \%$ release in $15 \mathrm{~min}$ ). In phosphate buffer ( $\mathrm{pH}$ 6.8), $\geq 85 \%$ of drug dissolved in $30 \mathrm{~min}$ and in vitro equivalence was established by calculating the difference factor $\left(f_{1}<15\right)$, similarity factor $\left(f_{2}>50\right)$, and dissolution efficiency $( \pm$ $10 \%)$. The tested brands met WHO BCS-based biowaiver criteria for in vitro dissolution testing, which ensured their pharmaceutical and therapeutic equivalence without in vivo screening and interchangeability with the innovator product.

KEYWORDS: In vitro equivalence, amlodipine tablets, biowaiver, drug release

\section{INTRODUCTION}

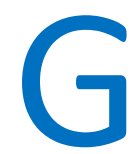

eneric pharmaceutical products are economical substitutes for innovator brands, being manufactured and marketed with different names after the end of the exclusive market rights held by the innovator company. Generic medicines must be biopharmaceutically equivalent to the innovator product to obtain the market authorization (1). The use of generic formulations is encouraged by the World Health Organization (WHO) as a measure to limit healthcare expenditures and improve access to medicine; however, cases have been identified where the quality of medications were compromised, especially those produced in middle- and low-income countries. Although, the economic requirement of price containment is undeniable, it is very important to safeguard the consumer's health. Therefore, the innovator product can only be substituted with their generic counterparts when meeting the pharmaceutical quality 
standards and therapeutic equivalence.

WHO estimated that in middle- and low-income countries approximately $10 \%$ of medical products are either falsified or substandard, and these products mainly reach the patients when there is inadequate access to quality medical products, weak technical capacity, and poor governance (2). Substandard products are authorized medical products; however, they do not meet the specifications and/or quality standards. Falsified products are those that intentionally or fraudulently misrepresent its source, composition, and even identity. Substandard and falsified medicines may not be able to treat the diseases for which they were intended and may even be harmful to patients; therefore, these medicines tend to damage the public confidence in health professionals, healthcare systems, and even medicines. Although, the occurrence of substandard and falsified medical products is more in low and middle-income nations, the impact is global. Consequently, to collect more accurate and validated information regarding the issue and to address the problem in a systemic manner, WHO launched the Global Surveillance and Monitoring System (GSMS) in 2013 (2, 3). Consequently, there is an urgent need for the quality of the generic products to be assured by evaluating various pharmaceutical quality parameters, such as friability, weight variation, content uniformity, assay, disintegration, and dissolution during the formulation processes and at regular intervals throughout the drug's shelf-life $(4,5)$.

Bioequivalence studies involving in vitro and in vivo evaluation of immediate-release oral dosage forms mainly focus on dissolution testing. Absorption of drugs into systemic circulation is determined by dissolution of the drug product under physiological conditions, in vivo release of the drug molecule from formulation, and permeability of the drug through the gastrointestinal tract (GIT). Subsequent to the introduction of Biopharmaceutics Classification System (BCS) by the United States Food and Drug Administration (FDA) and WHO, in vitro drug release studies have emerged as a useful tool in assessing the quality of oral dosage forms $(6$, 7). According to this system, in vivo bioequivalence studies for the oral pharmaceutical formulations containing active ingredients from BCS Classes I and III could be waived and a comparative in vitro dissolution test will be enough for establishing equivalence of generic products with innovator formulations. The studies used to establish equivalence in place of in vivo evaluation are known as biowaiver studies. Consequently, in vivo performance of the oral pharmaceutical preparations can be predicted by the in vitro dissolution profile and hence, in vitro drug release testing is an acceptable substitute for approving bioequivalence of generic products with reference products $(8-10)$.

Amlodipine belongs to dihydropyridinecarboxylic acid class of calcium channel blockers, which is a long-acting calcium antagonist with vascular selectivity and act through inhibition of transmembrane influx of $\mathrm{Ca}^{2+}$ into myocardium and vascular smooth muscles. Mainly, it is a long-acting antihypertensive agent, which is also used for treating vasospastic angina and coronary artery disease. Studies have also reported the antioxidative action of amlodipine, improving the status of oxidative stress in patients with essential hypertension $(11,12)$. Chemically, amlodipine is 3-0-ethyl 5-O-methyl 2-(2-aminoethoxymethyl)-4-(2-chlorophenyl)-6methyl-1,4-dihydropyridine-3,5-dicarboxylate (Fig. 1). 


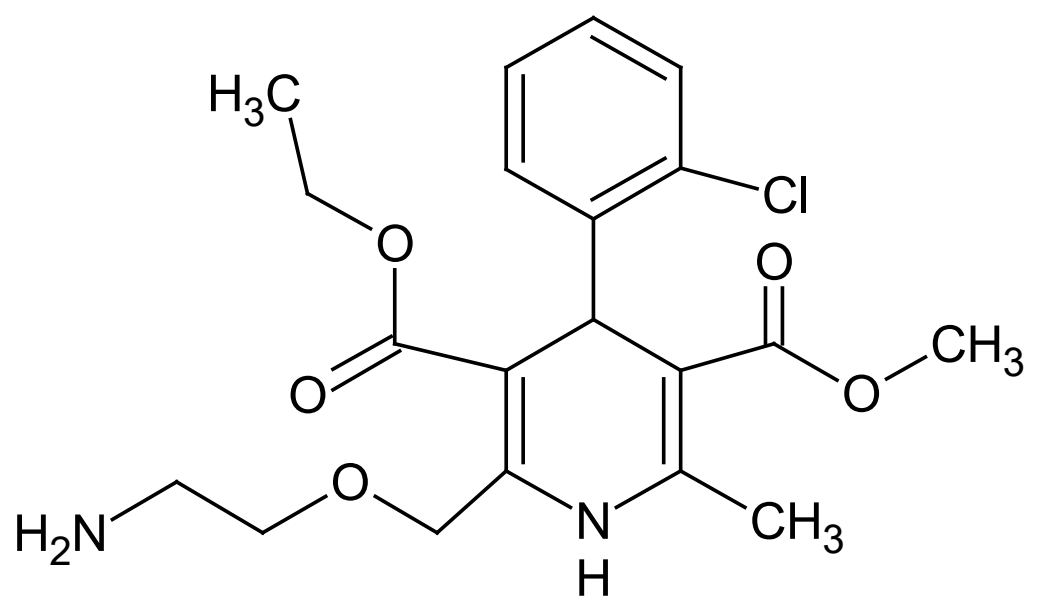

Figure 1. Chemical structure of amlodipine.

Amlodipine is a weakly basic drug (pKa 9.0 at $25 \stackrel{\circ}{\circ} \mathrm{C}$ ) that remains ionized within the GIT pH range. In the $\mathrm{pH}$ range of 1 to 6.8 , the lowest water solubility of amlodipine at $37 \stackrel{\circ}{\circ}$ is approximately $1 \mathrm{mg} / \mathrm{mL}$, and water solubility is reported as $75.3 \mathrm{mg} / \mathrm{mL}$ at 25 으; its logP value (n-octanol:water) is 2.96 (13-15). In Saudi Arabia, amlodipine is marketed as immediate-release tablet and capsule dosage forms and are available in the doses of 2.5, 5, and $10 \mathrm{mg}$. The 5-mg tablet of amlodipine is included in the WHO Model List of Essential Medicines for the treatment of hypertension. The dose-to-solubility ratio (D/S) for amlodipine at $\mathrm{pH} 1.2-6.8$ is low (5 and 10 $\mathrm{mL}$ for 5 and $10 \mathrm{mg}$ doses, respectively); therefore, according to WHO guidelines, amlodipine is considered to be 'highly soluble' (D/S ratio $\leq 250 \mathrm{~mL}$ ) (16). According to WHO, a drug substance is regarded as 'highly permeable' when its absorption is $85 \%$ or more. Although, the absolute bioavailability of amlodipine is 60-65\% (low), its permeability has been regarded as 'high', because of $90-95 \%$ excretion of the metabolite in urine (17). Consequently, on the basis of the solubility and permeability of amlodipine, WHO has kept it in BCS class I and therefore, equivalence of amlodipine tablets can be established through in vitro drug release testing under biowaiver conditions.

To the best of our knowledge, no such study has been performed on amlodipine tablets in the tested region. Therefore, the current study was undertaken to evaluate the quality of generic amlodipine tablets $(5 \mathrm{mg}$ ) commercially available in Saudi Arabian markets through various quality control tests and compare the results with innovator product (Norvasc). As in vitro dissolution testing is the most important parameter to establish the equivalence of pharmaceutical oral formulation with innovator product and evaluate the product quality, greater emphasis was given on the in vitro dissolution testing under biowaiver conditions. Statistical analysis was performed for comparing the obtained drug-release profiles of the test products with the innovator; similarity and difference factors $\left(f_{1}, f_{2}\right)$ and dissolution efficiency (DE) were evaluated.

The present study will provide scientific bases of the appropriateness of the tested products and substitution of these formulations with the innovator product to the patients, in case of cost- 
concern and non-availability. Furthermore, we hope that the present study will help to minimize the prevalence of spurious and substandard medical products.

\section{MATERIALS AND METHODS}

\section{Chemicals, Samples, and Equipment}

Four generic brands of amlodipine tablets $(5 \mathrm{mg}$ ) including Lofral (Lot. No.: OB0200A, Exp. Date: 02/2020, Acino, Aesch, Switzerland), Vascodipine (Lot. No.: 17GQ93, Exp. Date: 11/2020, Riyadh Pharma, Riyadh, Saudi Arabia), Amlocard (Lot. No.: 2487, Exp. Date: 04/2021, Batterjee Pharma, Jeddah, Saudi Arabia) and Lodipam (Lot. No.: 10177, Exp. Date: 03/2021, Saudi Pharmaceutical Industries, Riyadh, Saudi Arabia) were purchased from local pharmacies in Jazan, Saudi Arabia, and were randomly assigned codes as AM-1 to AM-4. Due to non-availability, the innovator product (Norvasc, 5 mg, Lot. No.: 19102, Exp. Date: 04/2022, Pfizer, Egypt) was procured from Egypt and coded as 'RP'. The samples were carefully examined for manufacturing and expiry dates and stored until further use. Pure amlodipine besylate (98.21\%) was purchased from MedChemExpress, LLC (NJ, USA). Hydrochloric acid ( $\mathrm{HCl})$, acetic acid, and potassium dihydrogen orthophosphate were procured from Sigma-Aldrich (USA), and sodium acetate trihydrate, orthophosphoric acid, and methanol were obtained from HiMedia Laboratories (Mumbai, India). Deionized water (double distilled grade) was prepared in-house using a water purification system (Smart2Pure 3 UV/UF, Thermo Scientific, Sweden). All the samples and tablets were weighed on Mettler Toledo analytical balance (XP105DR, Switzerland). Absorbance of assay and dissolution sample were recorded using UV-visible spectrophotometer (UV-1800 240V, Shimadzu Corporation, Kyoto, Japan).

\section{Calibration/Performance Verification Tests of Dissolution Apparatus and UV- Spectrophotometer}

The calibration and performance verification test for the dissolution apparatus are performed every 6 months on a routine basis following the procedure recommended by United States Pharmacopoeia (USP). For the performance verification test, USP Prednisone Tablets RS is used, and the dissolution test is performed under the following dissolution conditions: medium: purified water after deaeration; volume: $900 \mathrm{~mL}$; rotation speed: $50 \mathrm{rpm}$ (for USP apparatus 2), time point: $30 \mathrm{~min}$, temperature: $37 \pm 0.5 \stackrel{\circ}{ } \mathrm{C}$. After manual sampling, the release of prednisone is determined by measuring the absorbance at $242 \mathrm{~nm}$. Calibration of the UVspectrophotometer is also performed on a routine basis by following the standard operating procedure. The calibration process is carried out to evaluate absorbance and wavelength controls, stary light limit, photometric linearity, resolution power, and appropriateness of baseline and sample cells.

\section{Evaluation of Physicochemical Properties}

All drug products (generic and innovator) were subjected to physical tests such as weight variation, friability, and disintegration time according to well-established protocols $(4,18)$. To determine the weight variation, 20 tablets of each generic and innovator product were weighed together as well as individually using electronic balance. The percentage of deviation in the weight of individual tablets from the average weight was calculated. Ten previously weighed 
tablets were subjected to abrasion at $25 \mathrm{rev} / \mathrm{min}$ for $4 \mathrm{~min}$ by using Roche friability testing equipment (Copley Scientific, Nottingham, UK). The tablets were reweighed after dedusting to calculate the percent friability of each brand by comparing with their initial weight. The disintegration test was performed by using a USP apparatus (Basket-rack assembly, Copley scientific, Nottingham, UK). Six units from each tablet product were placed individually in 900 $\mathrm{mL}$ of distilled water at $37 \pm 2 \mathrm{o} C$. The apparatus was operated at $30 \mathrm{cycle} / \mathrm{min}$ on its vertical axis, and the time when no particles observed in the tubes was recorded as disintegration time (DT).

\section{Determination of Amlodipine Content}

The stock standard solution was prepared by taking an appropriate amount of amlodipine besylate and dissolving in a small amount of methanol by sonication. The volume was completed with $0.01 \mathrm{~N} \mathrm{HCl}$ to achieve a concentration of $100 \mu \mathrm{g} / \mathrm{mL}$. The calibration standards having the concentrations of $2,5,10$, and $20 \mu \mathrm{g} / \mathrm{mL}$ were prepared in $0.01 \mathrm{~N} \mathrm{HCl}$ in triplicate. The absorbance of all solutions was measured at $240 \mathrm{~nm}$, and the calibration graph was constructed by plotting absorbance against concentrations. Regression analysis was performed, and the correlation coefficient was determined. The intra- and inter-day precision and accuracy of the method was established by analyzing three quality control (QC) samples at low $(2 \mu \mathrm{g} / \mathrm{mL})$, mid $(10 \mu \mathrm{g} / \mathrm{mL})$, and high $(20 \mu \mathrm{g} / \mathrm{mL})$ concentrations. The QC samples were prepared using amlodipine besylate tablet powder in triplicate. The accuracy was expressed by calculating the recovery of analyte, and the precision of the method was measured by the relative standard deviation percentage (\%RSD) of the replicate analysis. Solution stability was determined by analyzing the working solution $(10 \mu \mathrm{g} / \mathrm{mL})$ after keeping aside at laboratory temperature $(25 \pm 2$ oc) for at least $12 \mathrm{~h}$.

Assay analysis was performed to determine the amlodipine content in all generic products and the innovator product. Tablets were crushed to fine powder and weighed equivalent to $5 \mathrm{mg}$ of amlodipine. The powder was sonicated in $5 \mathrm{~mL}$ of methanol for $10 \mathrm{~min}$ at room temperature. The volume was completed with $0.01 \mathrm{~N} \mathrm{HCl}$ to $50 \mathrm{~mL}$, and the solution was sonicated again for 5 min. The mixture was filtered through $0.45-\mu \mathrm{m}$ nylon filter and further diluted with $0.01 \mathrm{~N} \mathrm{HCl}$ to $10 \mu \mathrm{g} / \mathrm{mL}$ concentration. The absorbance of the solution was recorded at $240 \mathrm{~nm}$ using the UV-spectrophotometer in triplicate, and the amlodipine content was estimated using a standard calibration curve plotted between a range of concentrations of pure amlodipine solution versus their absorbances. The products were considered to satisfy acceptance criteria if assay results were within $90-110 \%$.

\section{In Vitro Dissolution Testing}

The USP dissolution apparatus 2 (paddle type) was used to test in vitro drug release of four generic and one innovator tablet formulations. Dissolution tests were performed as per WHO and U.S. FDA biowaiver guidelines by using the following dissolution media: $0.1 \mathrm{~N} \mathrm{HCl}(\mathrm{pH} 1.2$, simulated gastric fluid without enzyme, SGF), acetate buffer $(\mathrm{pH} 4.5)$, and phosphate buffer $(\mathrm{pH}$ 6.8 , simulated intestinal fluid without enzyme, SIF) $(6,7)$. The procedure described in the USPNF monograph for amlodipine immediate-release tablets was followed (5). The dissolution test was performed using 12 tablets in $500 \mathrm{~mL}$ of dissolution media. The apparatus operated at 75 
rpm, and the temperature was maintained at $37 \pm 2 \stackrel{\circ}{ } \mathrm{C}$ throughout the tests. Sampling was done by withdrawing $5-\mathrm{mL}$ aliquots from each vessel at 10, 15, 20, 30, 45, and 60 min followed by immediate replacement with fresh media to maintain the sink condition. The solutions filtered through $0.45-\mu \mathrm{m}$ nylon filter and absorbance were measured by the UVspectrophotometer against the respective dissolution medium as blank. The standard calibration graph was prepared between a range of drug concentrations, and their absorbance values were used to estimate the percentage of drug release.

The drug release curve was constructed by plotting the percentage of amlodipine dissolved against the sample withdrawal times. The U.S. FDA emphasizes comparing the drug-release profiles to establish equivalence between generic and refence products, therefore, a modelindependent method was adopted, and the difference factor $\left(f_{1}\right)$ and similarity factor $\left(f_{2}\right)$ were calculated. The $f_{1}$ value represents the difference in the two drug release curves at each time point, and $f_{2}$ is used to estimate the similarity in drug release between the two drug dissolution profile curves. An $f_{1}$ value close to zero and $f_{2}$ value near $100 \%$ ensure the sameness of the drug release profiles of generic and innovator products. Generally, the drug release profile of a generic formulation is considered to be similar to the innovator product when $f_{1}$ is $0-15$ and $f_{2}$ is 50-100 is obtained (19).

Release of amlodipine from generic tablets was compared with the innovator tablet according to biowaiver guidelines. Tablet formulations were considered to comply with the biowaiver conditions for drug product containing BCS Class 1 active pharmaceutical ingredient, if $\geq 85 \%$ the stated amount of the drug released in $30 \mathrm{~min}$ in $\mathrm{pH} \mathrm{1.2,4.5,} \mathrm{and} \mathrm{6.8;} \mathrm{furthermore,} \mathrm{the} \mathrm{drug}$ release profiles of generic products in all dissolution media must be similar to that of the innovator formulation (i.e., $f_{1} \leq 15$ and $f_{2} \geq 50$ ). If the generic and innovator brands are both release more $85 \%$ in 15 min under the same dissolution conditions, then statistical comparison of the dissolution profiles is not required.

The drug release profiles of generic tablets were further evaluated by calculating DE values, which is the area under the drug release curve $\left(A \cup C_{0-t}\right)$ up to time point, $t$. The DE represents the area (\%) of a rectangle $\left(R_{100}\right)$ designated as $100 \%$ drug release up to the same time point (20). The drug release profile of the generic product is considered equivalent to the innovator product when the DE value is within $\pm 10 \%$ of the innovator product (21).

\section{Statistical Analysis}

Statistical analyses of the assay, disintegration, and dissolution (30-min time point) data were performed by applying a one-way analysis of variance (ANOVA) followed by Tukey Kramer's test using GraphPad InStat 3.1 (GraphPad Software). A $p$-value less than 0.05 was considered to be statistically significant. The mean, standard deviation (SD), and \%RSD were calculated using Microsoft Excel 2010 (Microsoft Corporation). The data were presented as mean \pm SD or mean \pm $\%$ RSD, as applicable.

\section{RESULTS AND DISCUSSION}

The quality of pharmaceutical formulations is of utmost importance, as it is directly linked to the health of the consumer population. According to the findings of regulatory bodies such as WHO, 
the quality of drug products is under remarkable risks, especially in poor and developing countries. As a consequence, regular monitoring of drug quality is required. Hence, in the present investigation, generic brand amlodipine tablets available in Saudi Arabia were subjected to quality evaluation and compared with the innovator brand.

\section{Physicochemical Evaluation}

The physiochemical evaluation results (weight variation, friability, assay, and disintegration time) are shown in Table 1.

Table 1. Weight, Friability, Drug Content, and Disintegration Times of Generic (AM) and Innovator Brand Amlodipine Tablets

\begin{tabular}{|c|c|c|c|c|}
\hline Products & $\begin{array}{c}\text { Weight, mg } \\
(\text { mean } \pm \text { SD }) \\
(\boldsymbol{n}=\mathbf{2 0})\end{array}$ & $\begin{array}{c}\text { Friability, \% } \\
(\boldsymbol{n}=\mathbf{1 0 )}\end{array}$ & $\begin{array}{c}\text { Drug Content, \% } \\
(\text { mean } \pm \text { SD) } \\
(\boldsymbol{n}=\mathbf{3})\end{array}$ & $\begin{array}{c}\text { Disintegration time, min } \\
\text { (mean } \pm \text { SD) } \\
(\boldsymbol{n}=\mathbf{6})\end{array}$ \\
\hline AM-1 & $200.29 \pm 2.05$ & 0.03 & $98.3 \pm 0.75$ & $1.20 \pm 0.14$ \\
\hline AM-2 & $205.09 \pm 3.08$ & 0.01 & $98.0 \pm 0.58$ & $1.37 \pm 0.09$ \\
\hline AM-3 & $201.42 \pm 1.59$ & 0.07 & $98.8 \pm 0.95$ & $1.64 * \pm 0.17$ \\
\hline AM-4 & $212.33 \pm 1.92$ & 0.03 & $98.5 \pm 1.16$ & $1.34 \pm 0.25$ \\
\hline Innovator & $201.49 \pm 1.10$ & 0.02 & $98.7 \pm 0.65$ & $1.25 \pm 0.09$ \\
\hline
\end{tabular}

*Statistically significant difference $(p<0.05)$ between generic and innovator products for assay and disintegration data.

The tablet weight variations in all the tested brands were low ( $\leq 2.7 \%$ deviation) and complied with the specifications as for all the brands, none of the tablet weights deviated from average weight of the same brand by more than $5 \%$. The highest weight variation was observed for generic product AM-2 (2.7\%), and the lowest deviation in tablet weight was noticed for the innovator product (1.3\%). Similarly, when subjected to friability test, the percentage of weight loss for the tablets were very low $(\leq 0.07 \%)$, indicating that the tablets were sufficiently capable to withstand abrasion experienced during handling, packaging, and shipping for transportation. The friability test revealed that product AM-2 (0.01\%) was least friable, and AM-3 $(0.07 \%)$ had the highest friability. Consequently, the generic and innovator products were unlikely to lose particles from its surface during handling, keeping the general appearance and integrity of the tablets intact, and hence, have good consumer acceptability. According to official specifications, the tablet friability is considered to be acceptable if the product's weight loss is $<1 \%$.

The assay method was validated according to $\mathrm{ICH}$ guidelines (22). Regression analysis of the calibration curves exhibited a linear relationship over the concentration range of $2-20 \mu \mathrm{g} / \mathrm{mL}$ $\left(R^{2}=0.999\right)$. The intra- and inter-day accuracy of the assay method was ascertained by the recovery of analyte within $100 \% \pm 2 \%$, and $\%$ RSD values less than $2 \%$ indicated good precision of the method. The analytical solution was found to be stable for at least $12 \mathrm{~h}$ at laboratory temperature ( $25 \pm 2 \circ \mathrm{\circ}$ ) as the assay results were within $100 \% \pm 2 \%$.

Amlodipine content in the generic and innovator products was determined by UVspectrophotometric analysis, and the assay calculation was performed using the standard calibration curve $\left(R^{2}=0.999\right)$. The drug content of all tested products was within $90-110 \%$ of the labeled amlodipine amount, and therefore complied with official specifications (5). The highest percentage of amlodipine among the generic products was recorded in AM-3 $(98.8 \% \pm$ 
$0.95 \%)$, and the lowest assay result was observed in product AM-2 (98.0\% $\pm 0.58 \%)$. The drug content in the innovator product was found to be $98.7 \% \pm 0.65 \%$ of the label claim. Disintegration of tablets is considered to be the preliminary step towards dissolution; therefore, the disintegration time influences the drug release from an oral dosage form and subsequently affects bioavailability. The tested generic and innovator amlodipine tablets were fast disintegrating, as all the tablet brands completely disintegrated in 1.20-2.64 min and therefore passed this test according to the official specifications of immediate-release tablets ( $<30 \mathrm{~min}$ ). Among the generic products, the fastest disintegration was observed for AM-1 $(1.20 \pm 0.14$ $\mathrm{min})$, and the slowest disintegration time was recorded for AM-3 $(1.64 \pm 0.17, p<0.05)$. The innovator product completely disintegrated in $1.25 \mathrm{~min}$. Among all the products, the difference in the disintegration time was insignificant. Overall, the pharmaceutical quality of the tested formulations can be considered as good with regard to the above quality control tests.

\section{Dissolution Tests}

The dissolution test results $\left(f_{1}, f_{2}, \mathrm{DE}\right.$, drug release, and \%RSD) are shown in Table 2 . The rate of dissolution from the dosage forms directly influences the absorption of active pharmaceutical ingredients into the systemic circulation and hence, the bioavailability. In this study, dissolution profiles of the selected generic tablet formulations were evaluated by comparing with that of innovator amlodipine tablet according to biowaiver guidelines of the U.S. FDA and WHO.

Table 2. In Vitro Dissolution Test Results for Generic (AM) and Innovator Brand Amlodipine Tablets

\begin{tabular}{|c|c|c|c|c|c|c|}
\hline \multirow{2}{*}{$\begin{array}{l}\text { Dissolution } \\
\text { media }\end{array}$} & \multirow{2}{*}{ Parameters } & \multicolumn{5}{|c|}{ Products } \\
\hline & & AM-1 & AM-2 & AM-3 & AM-4 & Innovator \\
\hline \multirow{2}{*}{$\begin{array}{c}\mathrm{pH} 1.2 \mathrm{HCl} \\
\text { (simulated }^{\text {gastric fluid })^{+}}\end{array}$} & $\begin{array}{c}\text { Mean drug } \\
\text { release in } 30 \mathrm{~min} \\
\pm \% \mathrm{RSD}\end{array}$ & $98.4 \pm 1.08$ & $97.2 \pm 2.08$ & $\begin{array}{c}96.2 \pm \\
1.93\end{array}$ & $97.8 \pm 1.37$ & $\begin{array}{l}97.2 \pm \\
1.16\end{array}$ \\
\hline & $\mathrm{DE}(\%)$ & 83.0 & 82.8 & 82.2 & 82.3 & 82.2 \\
\hline \multirow{2}{*}{$\begin{array}{l}\mathrm{pH} 4.5 \\
\text { acetate } \\
\text { buffer }^{+}\end{array}$} & $\begin{array}{c}\text { Mean drug } \\
\text { release in } 30 \text { min } \\
\pm \% \text { RSD }\end{array}$ & $97.0 \pm 1.49$ & $97.8 \pm 1.10$ & $\begin{array}{c}96.6 \pm \\
2.67\end{array}$ & $96.7 \pm 1.55$ & $\begin{array}{c}97.5 \pm \\
1.74\end{array}$ \\
\hline & DE (\%) & 82.3 & 81.7 & 81.2 & 82.4 & 81.0 \\
\hline \multirow{4}{*}{$\begin{array}{c}\text { pH } 6.8 \\
\text { phosphate } \\
\text { buffer } \\
\text { (simulated } \\
\text { intestinal } \\
\text { fluid) }\end{array}$} & $\begin{array}{c}\text { Mean drug } \\
\text { release in } 30 \mathrm{~min} \\
\pm \% \mathrm{RSD}\end{array}$ & $93.4 \pm 3.12$ & $94.5 \pm 2.62$ & $\begin{array}{c}92.4^{*} \pm \\
3.16\end{array}$ & $\begin{array}{c}91.1^{*} \pm \\
3.32\end{array}$ & $\begin{array}{c}94.9 \pm \\
3.49\end{array}$ \\
\hline & $\begin{array}{l}\text { Difference factor } \\
\text { (f1) }\end{array}$ & 77 & 84 & 75 & 60 & - \\
\hline & $\begin{array}{l}\text { Similarity factor } \\
(f 2)\end{array}$ & 2 & 1 & 2 & 4 & - \\
\hline & DE (\%) & 78.6 & 78.0 & 78.8 & 75.6 & 78.2 \\
\hline
\end{tabular}

*Statistically significant difference $(p<0.05)$ between reference and test products.

${ }^{+}$Drug release in $\mathrm{pH} 1.2 \mathrm{HCl}$ and $\mathrm{pH} 4.5$ buffer is $\geq 85 \%$ in 15 min under same dissolution condition; therefore, drug release profiles of the test products were deemed to be equivalent to the innovator brand without statistical treatment.

$D E$ : dissolution efficiency. 
Cumulative drug release was calculated using a standard calibration curve prepared by plotting absorbance against concentrations of the calibration standard solutions in the range of 2-20 $\mu \mathrm{g} / \mathrm{mL}$. The calibration standards were prepared in three dissolution media separately $(\mathrm{pH} 1.2$, 4.5, and 6.8) and analyzed by UV-spectrophotometer at $240 \mathrm{~nm}$. Regression analysis was performed, and the correlation coefficient was recorded as 0.999 in $\mathrm{pH} 1.2 \mathrm{HCl}$ (SGF) and $\mathrm{pH} 4.5$ acetate buffer and 0.998 in phosphate buffer (pH 6.8, SIF). At pH 1.2 and pH 4.5, all products released $>85 \%$ of the labeled amount of amlodipine in $15 \mathrm{~min}$; therefore, their dissolution profiles are considered as similar to the innovator product (> 85\% release in $15 \mathrm{~min}$ ) without statistical treatment.

The mean $( \pm S D$ ) percentage of drug release for the generic products in $\mathrm{pH} 1.2$ at 15 min were $96.6 \% \pm 1.43$ for AM-1, 94.4\% \pm 2.35 for AM-2, $93.5 \pm 2.11$ for AM-3, and $93.3 \pm 1.76 \%$ for AM-4. In pH 4.5 at $15 \mathrm{~min}$, drug release was $92.1 \% \pm 2.26$ for $\mathrm{AM}-1,94.4 \% \pm 2.11$ for AM-2, 92.9\% \pm 2.43 for AM-3, and $93.3 \pm 2.16$ for AM-4. For the innovator product, $94.2 \%$ and $92.0 \%$ of the labeled amount of amlodipine was released in pH 1.2 and 4.5 at $15 \mathrm{~min}$, respectively.

In $\mathrm{pH} 6.8$, the generic and innovator products released $>85 \%$ amlodipine in $30 \mathrm{~min}$. For the generic products, the amount of drug dissolved in $\mathrm{pH} 6.8$ at 30 min was $93.4 \% \pm 3.12$ for AM-1, $94.5 \% \pm 2.62$ for $\mathrm{AM}-2,92.4 \% \pm 3.16$ for $\mathrm{AM}-3$, and $91.1 \% \pm 3.32$ for $\mathrm{AM}-4$ and $94.9 \% \pm 3.49$ for the innovator product. In the $\mathrm{pH} 6.8$ phosphate buffer, the $f_{1}$ and $f_{2}$ values indicated that the generic products were similar to the innovator product (Fig. 2). The lowest $f_{1}(1)$ and highest $f_{2}$ (84) values were observed for product AM-2, indicating that its dissolution profile is closest to the innovator brand among the tested generic products; product AM-4 exhibited the highest $f_{1}$ (4) and lowest $f_{2}(60)$ values.

In an in vitro dissolution study, DE provides another parameter to analyze and compare the drug release of generic and innovator brands based on the AUC; therefore, DE is helpful in the prediction of in vivo drug release. In this study, DE values of test products were within $\pm 10 \%$

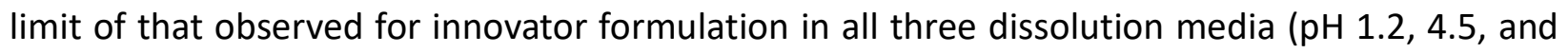
6.8). Consequently, the rate of drug release from the generic and innovator amlodipine tablets was similar on the basis of their DE values. The validity of the dissolution results was demonstrated by low \%RSD at all time points ( $\leq 20 \%$ at $15 \mathrm{~min}$ and $\leq 10 \%$ for higher time points). The \%RSD of drug dissolved at 30 min for products was in the range of $1.08-3.49 \%$.

Overall, the tested generic products met the WHO BCS class-based biowaiver criteria for in vitro drug dissolution. Therefore, the tested generic products can be considered as equivalent to the innovator product. The efficacy associated with the use of the generic formulations would be comparable to the innovator brand. For the tested products, in vivo bioavailability assessment is not required to ascertain therapeutic effectiveness and interchangeability with the innovator brand in case of unavailability or when cost is a concern. 


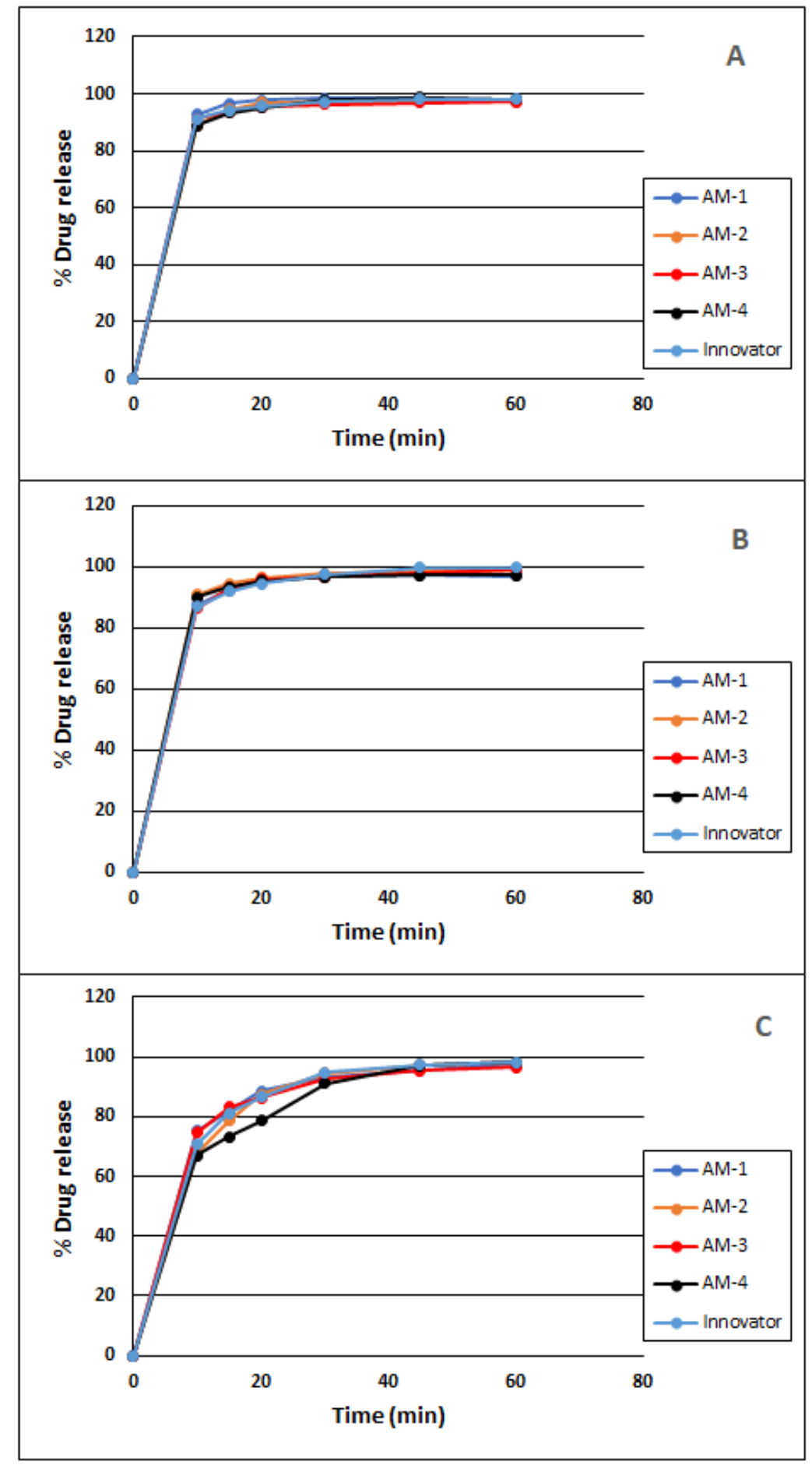

Figure 2. Dissolution profile of generic (AM) and innovator brands of amlodipine tablets in A) $\mathrm{pH} 1.2 \mathrm{HCl}$ (simulated gastric fluid without enzyme), B) pH 4.5 acetate buffer, and C) pH 6.8 phosphate buffer (simulated intestinal fluid). Dissolution condition: USP II apparatus, $75 \mathrm{rpm}, 500 \mathrm{~mL}$ medium at $37 \pm 2 \stackrel{\circ}{\mathrm{C}}$. 


\section{CONCLUSION}

Four generic brands of amlodipine tablets $(5 \mathrm{mg})$ were evaluated for their physicochemical properties and found to comply with USP specifications with regard to weight variation, friability, assay, and disintegration time. In vitro drug release of all the generic tablet products was similar to the innovator brand according to WHO biowaiver conditions for formulations containing a BSC class 1 active ingredient. In $\mathrm{pH} 1.2 \mathrm{HCl}$ and $\mathrm{pH} 4.5$ acetate buffer, $\geq 85 \%$ amlodipine released within $15 \mathrm{~min}$; therefore, their dissolution profiles were similar without statistical treatment. In $\mathrm{pH} 6.8$ phosphate buffer, the drug release was $\geq 85 \%$ within $30 \mathrm{~min}$, and $f_{1}, f_{2}$, and $\mathrm{DE}$ values indicated similarity of the dissolution profiles. The tested generic formulations were considered to be therapeutically and pharmaceutically equivalent to the innovator product (Norvasc) without in vivo screening. Overall, the products were of good quality and interchangeable with each other.

\section{CONFLICTS OF INTEREST}

The authors disclosed no conflicts of interest related to this article.

\section{REFERENCES}

1. Danchev, N.; Nikolova, I. Generics-Present and Future. Biotechnol \& Biotechnol. Equip. 2007, 21, 94-99. DOI: $10.1080 / 13102818.2007 .10817423$.

2. Substandard and falsified medical products. World Health Organization. January 31, 2018. https://www.who.int/news-room/fact-sheets/detail/substandard-and-falsified-medical-products (accessed May 11, 2021).

3. Global Surveillance and Monitoring System for Substandard and Falsified Medical Products. World Health Organization: Geneva, Switzerland, 2017.

4. Uddin, M. S.; Mamun, A. A.; Hossain, M. S.; Asaduzzaman, M.; Sarwar, M. S.; Rashid, M.; Herrera Calderon, $\mathrm{O}$. In vitro quality evaluation of leading brands of ciprofloxacin tablets available in Bangladesh. BMC Res. Notes. 2017, 10, 185-193. DOI: 10.1186/ s13104-017-2507-y.

5. The United States Pharmacopeia and National Formulary USP 35-NF 30; The United States Pharmacopeial Convention, Inc.: Rockville, MD, 2012.

6. Waiver of In vivo Bioavailability and Bioequivalence Studies for Immediate-Release Solid Dosage Forms Based on a Biopharmaceutics Classification System; Guidance for Industry, U.S. Department of Health and Human Services, Food and Drug Administration, Center for Drug Evaluation and Research (CDER), U.S. Government Printing Office: Washington, DC, 2000.

7. WHO Expert Committee on Specifications for Pharmaceutical Preparations. Proposal to waive in vivo bioequivalence requirements for WHO Model List of Essential Medicines immediate-release, solid oral dosage forms; WHO Technical Report Series, No. 937, Annex 8; World Health Organization: Geneva, Switzerland, 2006.

8. Yu, L. X.; Amidon, G. L.; Polli, J. E.; Zhao, H.; Mehta, M. U.; Conner, D. P.; Shah, V. P.; Lesko, L. J.; Chen, M. L.; Lee, V. H. L.; Hussain, A. S. Biopharmaceutics Classification System: The scientific basis for biowaiver extensions. Pharm. Res. 2002, 19, 921-925. DOI: 10.1023/a:1016473601633.

9. Gupta, E.; Barends, D. M.; Yamashita, E.; Lentz, K. A.; Harmsze, A. M.; Shah, V. P.; Dressman, J. B.; Lipper, R. A. Review of global regulations concerning biowaivers for immediate release solid oral dosage forms. Eur. J. Pharm. Sci. 2006, 29, 315-324. DOI: 10.1016/j.ejps.2006.05.001.

10. Polli, J. E. In vitro studies are sometimes better that conventional human pharmacokinetic in vivo studies in assessing bioequivalence of immediate-release solid oral dosage forms. The AAPS J. 2008, 10, 289-299. DOI: 10.1208/s12248-008-9027-6. 
11. Fares, H.; DiNicolantonio, J. J.; O'Keefe, J. H.; Lavie, C. J. Amlodipine in hypertension: a first-line agent with efficacy for improving blood pressure and patient outcomes. Open Heart. 2016, 3, e000473. DOI: 10.1136/openhrt-2016-000473.

12. Mahajan, A. S.; Babbar, R.; Kansal, N.; Agarwal, S. K.; Ray, P. C. Antihypertensive and antioxidant action of amlodipine and vitamin $C$ in patients of essential hypertension. J. Clin. Biochem. Nutr. 2007, 40, 141-147. DOI: $10.3164 / j c b n .40 .141$.

13. Shohin, I. E.; Ramenskaya, G. V.; Vasilenko, G. F.; Malashenko, E. A. In vitro dissolution kinetics of amlodipine tablets marketed in Russia under biowaiver conditions. Dissolut. Technol. 2010, 17, 20-22. DOI: 10.14227/DT170310P20.

14. Amlodipine. PubChem website. National Center for Biotechnology Information. https://pubchem.ncbi.nlm.nih.gov/compound/Amlodipine (accessed April 25, 2020).

15. Caron, G.; Ermondi, G.; Damiano, A.; Novaroli, L.; Tsinman, O.; Ruell, J. A.; Avdeef, A. Ionization, lipophilicity, and molecular modeling to investigate permeability and other biological properties of amlodipine. Bioorg. Med. Chem. 2004, 12, 6107-6118. DOI: 10.1016/j.bmc.2004.09.004.

16. WHO Expert Committee on Specifications for Pharmaceutical Preparations. WHO Model List of Essential Medicines, World Health Organization: Geneva, Switzerland, 2007.

17. Jung-Cook, H.; Mayet-Cruz, L.; Girard-Cuesy, M. E. Comparative in vitro dissolution and in vivo bioavailability of commercial amlodipine tablets. Trop. J. Pharm. Res. 2018, 17, 1685-1691. DOI: 10.4314/tjpr.v17i9.1.

18. Karmakar, P.; Kibria, M. G. In vitro comparative evaluation of quality control parameters between paracetamol and paracetamol/caffeine tablets available in Bangladesh. Int. Curr. Pharm. J. 2012, 1, 103109. DOI: 10.3329/icpj.v1i5.10282.

19. Dissolution Testing of Immediate Release Solid Oral Dosage Forms; Guidance for Industry. U.S. Department of Health and Human Services, Food and Drug Administration, Center for Drug Evaluation and Research (CDER), U.S. Government Printing Office: Washington, DC, 1997.

20. Costa, P.; Sousa Lobo, J. M. Modeling and comparison of dissolution profiles. Eur. J. Pharm. Sci. 2001, 13, 123-133. DOI: 10.1016/s0928-0987(01)00095-1.

21. Anderson, N. H.; Bauer, M.; Boussac, N.; Khan-Malek, R.; Munden, P.; Sardaro, M. An evaluation of fit factors and dissolution efficiency for the comparison of in vitro dissolution profiles. J. Pharm. Biomed. Anal. 1998, 17, 811-822. DOI: 10.1016/s0731-7085(98)00011-9.

22. International Conference on Harmonisation of Technical Requirements for Registration of Pharmaceuticals for Human Use. Validation of Analytical Procedures: Text and Methodology, Q2(R1); ICH Harmonised Tripartite Guideline: Geneva, Switzerland, 2005. 